\title{
Ranaivoson, Dominique (dir.). - Senghor et sa postérité littéraire
}

\section{Kalidou Sy}

\section{(2) OpenEdition}

1 Journals

Édition électronique

URL : http://journals.openedition.org/etudesafricaines/14443

DOI : 10.4000/etudesafricaines. 14443

ISSN : $1777-5353$

Éditeur

Éditions de l'EHESS

\section{Édition imprimée}

Date de publication : 5 octobre 2012

Pagination : 1030-1032

ISBN : 978-2-7132-2350-1

ISSN : 0008-0055

\section{Référence électronique}

Kalidou Sy, "Ranaivoson, Dominique (dir.). - Senghor et sa postérité littéraire », Cahiers d'études africaines [En ligne], 208 | 2012, mis en ligne le 31 octobre 2012, consulté le 24 septembre 2020. URL : http://journals.openedition.org/etudesafricaines/14443 ; DOI : https://doi.org/10.4000/ etudesafricaines. 14443

Ce document a été généré automatiquement le 24 septembre 2020.

(c) Cahiers d'Études africaines 


\title{
Ranaivoson, Dominique (dir.). - Senghor et sa postérité littéraire
}

\author{
Kalidou Sy
}

\section{RÉFÉRENCE}

RANAIVOSON, Dominique (dir.). - Senghor et sa postérité littéraire. Actes du colloque de Cerisy-La-Salle. Metz, Université Paul Verlaine, Centre Écritures (« Littératures des mondes contemporains, Afriques, $3 »), 2008,196 \mathrm{p}$.

1 La célébration du centenaire de la naissance du poète-président a été l'occasion de réunir à Cérisy un colloque pour réfléchir sur la postérité littéraire de Senghor. Suivant l'intitulé même de ce numéro qui rend compte de cette rencontre et qu'a dirigé Dominique Ranaivoson, il s'agissait de faire le point sur l'héritage de Léopold Sédar Senghor, poète et théoricien de la Négritude.

2 Aussi le contrat d'objectif fixé par et dès le titre peut-il se lire globalement suivant un malentendu ou une série de malentendus entre Senghor et bon nombre d'intellectuels africains, surtout dans les générations beaucoup plus jeunes que la sienne. Le spectre de ce malentendu va du rejet total qui confine à la détestation à l'instar des écrivains congolais ou camerounais en général, à la revendication passionnée d'une filiation suivant l'exemple du jeune écrivain malgache

Johary Ravaloson, ou encore plus essentiellement de Nimrod. En cela, la contribution de Nicolas Martin-Granel «Senghor et les écrivains congolais: le malentendu » est significative. La Négritude est toujours perçue suivant la connotation péjorative voire négative liée au mot Nègre. Dans le contexte du nationalisme culturel et de l'assimilation politique du Congo ou du Cameroun comme d'un certain nombre de pays africains dans la tourmente du marxisme ou du panafricanisme, la réhabilitation et la visibilisation des racines africaines et des cultures négro-africaines par le mouvement de la Négritude ne peuvent être comprises que comme voilement et comme stratégie neo-coloniale. Surtout si ce mouvement est porté par quelqu'un comme Senghor qui est 
classé d'emblée comme représentant de la France et du neo-colonialisme. Son statut de premier Africain agrégé de grammaire ne lui facilite pas les choses, au contraire.

Dès lors des écrivains et intellectuels comme Sony Labou Tansi, Emmanuel Dongala, Stanislas Adotevi, Marcien Towa, Paulin Hountondji, Henri Lopès, Yves Mudimbe jusqu'à Ngoïe-Ngalla et Patrice Nganang se font les échos des médias populaires et de l'opinion publique. C'est ainsi que la célébration de l'Afrique, de la femme noire et la rénovation de la sensibilité nègre (Boniface Mongo-Mboussa), la revendication d'un certain primitivisme et de ses implications esthétiques et éthiques (Julien de St-Jores), comme la célèbre anthologie de 1948 et son parrainage par Jean-Paul Sartre avec sa préface " Orphée noir » devenue paradigmatique dans la lecture des littératures négroafricaines (Dominique Ranaivoson), tout cela n'est plus lu que comme participant d'une entreprise de mystification qui contribue encore davantage à inférioriser l'homme noir, le Nègre, aux yeux de l'Occident par une spécification trompeuse et illusoire qui le tient dans la minorité intellectuelle et mentale. Les mêmes sinon similaires critiques sont reprises contre Senghor, et contre Césaire aussi, par les tenants de l'Antillanité et de la Créolité (Jean Michel Devésa) comme du reste la Francophonie en tant qu'institution a plutôt desservi Senghor et a contribué très fortement à l'ignorance de ses œuvres et de sa théorie aux Amériques actuellement (Daniel Delas). On comprend alors que certains puissent parler de "complexe de Senghor", probablement comme l'on parlerait du " complexe de Procuste » ou du « complexe d'ÆEdipe ». Senghor est alors accusé de tous les maux, rendu responsable de tous les problèmes survenus en Afrique, jusqu'au génocide rwandais perçu comme « le tombeau de la Négritude » (Patrice Nganang).

Mais ce malentendu est perceptible aussi dans la célébration enthousiaste de l'œuvre de Senghor par certains intellectuels et écrivains. Le poète de la Négritude mais plus encore le penseur de la civilisation de l'universel et du métissage culturel est devenu la référence pour beaucoup, à commencer par ses anciens contestataires comme Adotevi, Lopès et même Wole Soyinka, jusqu'à ses fils spirituels comme Nimrod (Edem Awumey, André Patient-Bokiba). Par calcul ou par sincérité, allez savoir! C'est pourquoi et de plus en plus le discours senghorien est lu, au regard de la déconstruction du face-à-face Blanc/Noir sinon Occident/Afrique, dans le sillage du postcolonialisme aux côtés de Bhabha, Spivak, Saïd, et même Irele Abiola et Mudimbe marquent combien les nouveaux discours des intellectuels négro-africains ou du moins africains restent intimement aujourd'hui tributaires de Senghor et de sa pensée (Boniface MongoMboussa).

Finalement ce numéro, en tentant d'analyser l'héritage littéraire de Senghor, ne souligne que le malentendu qui habite les relations qu'un certain nombre d'intellectuels et d'écrivains négro-africains ont entretenu avec l'homme politique Senghor, mais plus encore avec le président au cœur de la gestion des affaires publiques, occultant de ce fait l'analyse distanciée de l'œuvre.

On peut alors regretter très fortement que la plupart des interventions restent dans la généralité des idées reçues sans daigner interroger l'œuvre littéraire du poète et des autres écrivains pour mesurer sur pièce son influence. Certaines interventions d'ailleurs manifestent une profonde ignorance des relations intellectuelles, artistiques et littéraires entre générations d'écrivains ou entre littératures simplement, entre l'Afrique subsaharienne et le Maghreb, par exemple. Un examen, même rapide de certaines publications, aurait permis d'éviter quelques conclusions hâtives comme dans l'intervention de Mohamed Daoud ou des critiques passées de saison et qui n'ajoutent 
rien à la pertinence du propos comme dans celle de Patrice Nganang. Ce qui prouve encore davantage qu'il faut lire ce numéro 3 de la série "Afrique ", dans la collection «Littérature des mondes contemporains » de l'Université Paul Verlaine de Metz, et le lire avec attention et intérêt. 